\title{
A filosofia de Match point: síntese do imaginário trágico de Woody Allen
}

\section{The philosophy of Match point: synthesis of the tragic imaginary of Woody Allen}

\author{
Rogério de Almeida ${ }^{1}$, Marcos Beccari ${ }^{2}$
}




\section{Resumo}

O objetivo deste artigo é tanto propor uma interpretação filosófica de Match point quanto demonstrar como tal película sintetiza o imaginário trágico de Woody Allen. De início, delineamos algumas bases conceituais que amparam a proposta de uma interpretação fílmica. Em seguida, apresentamos os elementos que caracterizam o pensamento trágico e os associamos ao filme elencado. Observamos, por fim, que o imaginário trágico que permeia a obra de Woody Allen desponta pela aprovação incondicional da existência.

Palavras-chave

Match point, Woody Allen, imaginário trágico.

\section{Abstract}

The aim of this article is to propose a philosophical interpretation of Match point and demonstrate how this movie synthesizes the tragic imaginary of Woody Allen. At first, we clarify some conceptual bases that support the proposal of a filmic interpretation. Then we present the elements that characterize the tragic thought and we associate them with the selected movie. We argue, finally, that the tragic imaginary that permeates Woody Allen's work is revealed by the unconditional approval of existence.

\section{Keywords}

Match point, Woody Allen, tragic imaginary. 
O objetivo deste artigo é propor uma interpretação, sob o viés da filosofia trágica, na qual se inserem Nietzsche e Rosset, acerca do filme Match point (2005) de Woody Allen. Mais do que isso, defendemos que tal película sintetiza o imaginário trágico - conjunto de imagens, símbolos e metáforas que expressa um pensamento trágico - que permeia a produção cinematográfica de Allen. $\mathrm{O}$ que nos interessa, portanto, não é tanto a trama e o discurso circunscritos no filme quanto o pensamento que o agencia filosoficamente e que nele adquire alguma expressão. Em outros termos, trata-se de sua poética narrativa: aquilo que o filme "diz" importa menos que o pensamento que se abre a partir dele ou diante dele, nos termos de Paul Ricoeur (2008, p. 68): "Esta proposição não se encontra atrás do texto, como uma espécie de intenção oculta, mas diante dele, como aquilo que a obra desvenda, descobre, revela".

Significa que este estudo pode ser situado no limiar entre os estudos fílmicos (REIA-BAPTISTA, 2005) e uma hermenêutica fílmica que nos possibilite mirar, a partir de uma película, em direção a uma interpretação filosófica. Reside aí o pressuposto filosófico de que o cinema, conforme o compreendia Deleuze (1985), é um modo específico de pensar, aprender, imaginar, criar etc. A especificidade desse modo teria se consolidado, grosso modo, quando o cinema moderno deixou de meramente transmitir um pensamento e passou a evidenciar o lugar em que ele se desencadeia: fora da tela, na interação com o espectador.

No caso de Woody Allen, cuja expressiva obra já conta com mais de 50 filmes, não é difícil identificar certos aspectos que marcam o que se pode chamar de estilo do diretor, ou seja, sua maneira de pensar cinematograficamente sobre a vida. Quanto a isso, o próprio cineasta nos fornece, em entrevista a Lax (2008, p. 407), um quadro preciso: "se eu fosse fazer uma sátira dos meus filmes faria os letreiros em preto-e-branco, com algum tipo de jazz, Duke Ellington, digamos, e depois provavelmente alguém fazendo para o público um discurso sobre o sentido da vida em geral". Mas para além desses aspectos estilísticos, o que se sobressai na obra de Allen é certo olhar despretensioso - donde todos os 
seus filmes serem comerciais e artisticamente despretensiosos - que enaltece a experiência sensível (estética) e, ao mesmo tempo, a ausência de sentido da vida.

Seu diálogo com o espectador nunca se pauta na ideia de que algum sentido teria se perdido, e sim na constatação de que qualquer sentido que queiramos encontrar nunca existiu. Em vez de queixa ou lamentação, com efeito, a poética de Allen lança mão de inúmeros discursos sobre o sentido da vida justamente para torná-los inócuos, isto é, mostrando que a experiência vivida prescinde de qualquer sentido. É como se ele quisesse nos mostrar, em suma, que a vida não é feita para ter um sentido, mas para ser vivida.

Quanto a esse posicionamento filosófico, nenhum outro filme parece ser mais esclarecedor que Match point (2005), em relação ao qual Woody Allen se refere com um apreço especial, algo bem diferente do que acontece com seus outros filmes - o cineasta sempre fala deles a partir das suas impressões de quando os fez, afirmando não voltar a assisti-los depois de prontos: "eu esperava usar Ponto final para colocar pelo menos um ou dois pontos do que constitui minha filosofia pessoal, e sinto que consegui fazer isso" (Ibid., 2008, p. 174).

Com base nessa afirmação, colocamo-nos a tarefa de interpretar filosoficamente Match point (2005); não no sentido de inventariar as possíveis referências que o amparam, e sim no intuito de salientar o pensamento trágico que ali se abre, desvelase e impõe-se. "Sempre vou fazer filmes que expressem os meus sentimentos pessoais sobre a falta de sentido da vida e o horror da existência" (Ibid., 2008, p. 402) - a isso acrescentamos que Match point (2005) não se esgota na constatação do trágico, mas se destaca por aprová-lo. Nisso consiste a filosofia trágica de Woody Allen: a aprovação da existência mesmo em seus aspectos mais duros e indesejáveis. Antes de explorarmos tal perspectiva, porém, cumpre esclarecermos algumas bases conceituais que amparam a proposta de uma interpretação fílmica.

\section{Poética e interpretação fílmica}

Compreendemos poética aqui como modo de fazer ou arte de composição, tendo como pressuposto que o cinema de ficção apresenta alguma dimensão 
narrativa em sua elaboração, isto é, conta uma história com recursos visuais, imagéticos, sonoros etc. O cinema realiza, portanto, um diálogo entre o mundo próprio do cinema (diegese) e o mundo concreto, que inclui o espectador ou o mundo do espectador. "O cinema seria, então, a articulação entre o real que Ihe ultrapassa e o interior de quem o vê" (ALMEIDA, 2017, p. 13-14).

A poética narrativa do cinema opera como uma "máquina de linguagem" que produz "estados poéticos" (MERLEAU-PONTY, 1983, p. 115), isto é, o cinema não expõe ideias, não apresenta pensamentos, mas mostra a conduta e o comportamento do homem "e nos oferece diretamente esse modo peculiar de estar no mundo, de lidar com as coisas e com os seus semelhantes" (Ibid., p. 116).

No entanto, nenhuma obra fílmica pode ser feita de modo exclusivamente autorreferencial. Sempre há algo que Ihe escapa, um exterior cujo sentido só pode ser dado pela participação do espectador. Isso significa que o espectador não se envolve apenas cognitiva ou intelectualmente, mas sobretudo emocionalmente, perfazendo um complexo que é de ordem estética, isto é, um processo orgânico que pode potencializar ou diminuir a vitalidade humana, seja física ou psiquicamente (ALMEIDA, 2015b). Essa participação de corpo inteiro do espectador o torna tradutor, no sentido do termo dado por Steiner (2005, p. 72): "entre línguas ou no interior de uma língua, a comunicação humana é igual à tradução".

O espectador compreende uma obra pois a traduz, ou seja, comunica-se com ela e a comunica por outros meios. Uma obra narrativa tem, portanto, duas faces: uma voltada para dentro e outra para fora. É na porosidade entre essas dimensões que se instaura a hermenêutica, isto é, a dimensão interpretativa. Sob esse prisma, podemos afirmar que quem dá voz à obra cinematográfica é seu intérprete, o espectador que se põe diante dela, interrompendo seu fluxo, desviando-o para as paragens que Ihe propiciem compreender o "mundo da obra" (RICOEUR, 2008) a partir de sua própria experiência de mundo.

No entanto, a hermenêutica não está em condições de arbitrar pela interpretação correta, justamente porque toda interpretação é uma construção 
de sentido (ou de sua ausência) empreendida pelo intérprete diante de uma obra, a partir do modo como ela o afeta, como anestesia ou potencializa sua vitalidade (ALMEIDA, 2015b). Nessa perspectiva, a hermenêutica trágica "é o 'silêncio que fala', ou seja, o compreender que privilegia o momento oportuno em detrimento de um sentido fixo" (BECCARI, 2016, p. 154). É essa dinâmica que alimenta as obras e as mantém vivas: um constante renovar-se compreensivo ocasionado pelos momentos interpretativos.

se tudo pode ser interpretado, é precisamente porque não há o que ser interpretado - sendo um dos aspectos do trágico 'o que se furta a toda tentativa de interpretação' [Rosset]. [...] Com efeito, por 'hermenêutica trágica' devemos entender apenas uma hermenêutica que, como a de Ricoeur, não pressupõe um conteúdo específico a ser interpretado, mas que, em vez disso, encare o compreender como um modo-de-ser (Ibid., p. 145).

Não se trata, portanto, entre as perspectivas possíveis - estética, sociológica, psicanalista, estruturalista, formalista etc. - de estabelecer a priori interpretativos que zelem pela supremacia do(s) sentido(s) investigado(s), mas de acatar que toda e qualquer visão de mundo é igualmente válida sob o viés de uma hermenêutica trágica - "mesmo aquela que leva em conta certo universalismo ou determinismo, porque não vemos nela a expressão particular de uma ordem geral assim 'revelada', mas apenas uma manifestação casual de organização que não remete a nenhuma ordem exterior a ela" (Ibid., p. 148).

No caso de Match point (2005) de Woody Allen, objeto deste estudo, a película desenvolve um tema já trabalhado anteriormente pelo diretor em Crimes e pecados de 1989, entretanto em outra chave, já que Match point é um drama, um dos poucos entre a expressiva sucessão de comédias de Allen e certamente um de seus melhores filmes. "Match point é provavelmente o melhor filme que eu fiz. Isso é estritamente acidental, só aconteceu de dar certo" (ALLEN apud SCHEMBRI, 2006, p. 2, tradução nossa), afirmação que coaduna com a própria premissa do filme: a de que grande parte da vida é determinada pela sorte. 


\section{O trágico em Match point (2005)}

Nossa tese é a de que Woody Allen sintetizou em Match point (2005), como em nenhum outro filme, o imaginário trágico que permeia sua produção cinematográfica.

O trágico vem expresso filosoficamente em Nietzsche (1995, p. 118) como a "fórmula da afirmação máxima, da plenitude, da abundância, um dizer sim sem reservas, até mesmo ao sofrimento, à própria culpa, a tudo o que é problemático e estranho na existência". Clément Rosset (1989, p. 8) sintetizou esse pensamento como a "ligação entre a alegria de existir e o caráter trágico da existência", apontando que o trágico "recusa de saída todas as qualidades que foram, ao longo do tempo, mais ou menos vinculadas ao conceito de trágico: tristeza, crueldade, obscuridade, inelutabilidade, irracionalidade" (Ibid., p. 66).

Com outras palavras, é o que Woody Allen defendeu em entrevista a Lax (2008, p. 172):

nós temos de aceitar que o universo é sem deus, e a vida é sem sentido, muitas vezes uma experiência brutal e terrível, sem esperança [...] na verdade estou fazendo a pergunta: dado o pior, como podemos continuar, ou até mesmo por que deveríamos escolher continuar? Claro, nós não escolhemos - a escolha está impregnada em nós. O sangue escolhe viver

O trágico é, então, aprovação. Diante do que há de pior na existência, alguns optam pela ilusão, por uma ideia qualquer de salvação e agarram-se a essa esperança; outros aprovam a existência integralmente, com tudo que há de bom e de ruim. Essa aprovação pode se dar de numerosos modos, não só pelo discurso, mas principalmente pela ação, pelo modo de aderir à realidade.

É verdade que a filmografia de Allen não se limita à temática trágica, mas ela vem explicitada em muitos de seus filmes. Para ficarmos com os mais recentes, em Meia-noite em Paris (2011), Gil passa por um processo de transformação pelo qual termina por aprovar a insuficiência do presente, desfazendo-se da ilusão de que o passado era melhor (ALMEIDA, 2012). Em Magia ao Iuar (2014), a aprovação ocorre quando Stanley reconhece que a razão é insuficiente no controle das crenças e sentimentos. Dos mais antigos, A rosa púrpura do Cairo, 
de 1985, é outro bom exemplo ao mostrar que a fantasia pode até se impor por um tempo, mas acaba sucumbindo ao real, que termina por ser aprovado: "você tem que escolher entre a realidade e a fantasia e, claro, é forçado a escolher a realidade, e ela sempre te mata" (ALLEN apud LAX, 2008, p. 459).

Match point (2005) é um drama filmado na Inglaterra em 2005 e narra a história de Chris Wilton, um ex-jogador de tênis que ascende socialmente por meio do casamento com Chloe. Chris passa a ocupar um lugar de destaque nas empresas do sogro e mantém um relacionamento extraconjugal com Nola Rice, antiga namorada de seu cunhado. Quando Nola engravida de Chris, sua situação se complica: ela recusa-se a abortar e o cobra quanto ao término do casamento, decisão que ele dizia ter tomado. Como se não bastasse, a gravidez indesejada surge em contraste com a situação matrimonial de Chris, que sempre desejou ter um filho embora sua esposa fosse incapaz de engravidar.

Mas o dilema maior de Chris gira em torno da dificuldade de abrir mão de sua confortável condição social e financeira. Como solução, ele decide assassinar Nola. Para não levantar suspeitas, arquiteta um plano de assalto que inclui a vizinha de Nola, uma senhora idosa, que é morta por ele instantes antes de Nola. Para seu azar, a polícia descobre no apartamento de Nola um diário comprometedor e as suspeitas recaem sobre ele, mesmo com os indícios (forjados por Chris) de que o duplo homicídio tenha se dado em decorrência de um roubo. Entretanto, o jogo muda quando a aliança da senhora assassinada é encontrada com um traficante morto, fato que comprovaria a pretensa inocência de Chris.

Esse anel da vizinha possui um apelo simbólico notável. Quando Chris apressava-se em se livrar dos bens roubados, jogando-os no rio Tâmisa, o anel atinge a grade e cai distante da água. Trata-se de uma analogia evidente à bola de tênis acertando o topo da rede, conforme vemos na cena inicial do filme, na qual o protagonista anuncia:

O homem que disse "Eu prefiro ter sorte do que ser bom" sabia muito sobre a vida. As pessoas têm medo de encarar como grande parte dela depende da sorte. É assustador pensar que tantas coisas estão fora de 
controle. Existem momentos em um jogo em que a bola toca a rede e, por um segundo, ela pode ir para o outro lado ou voltar para o seu. Com um pouco de sorte, ela vai para o outro lado, e você ganha. Ou talvez não, e você perde (PONTO, 2005).

O anel que fica retido na grade torna-se a prova que absolve Chris em vez de condená-lo (como a analogia com a bola de tênis parecia indicar), graças ao traficante que, de modo totalmente fortuito, tomou o anel para si. Desse modo, o protagonista termina novamente agraciado pela sorte e a cena final mostra a família (ele, esposa, filho recém-nascido e sogros) retornando da maternidade, celebrando a chegada de uma nova vida.

Como em Crimes e pecados, que Woody Allen filmou em 1989, Match point faz referência a Crime e castigo de Dostoiévski. Mas enquanto no romance a personagem se recompõe pela expiação de seu pecado, negando a premissa niilista que motiva o duplo assassinato, em Match point o mesmo duplo assassinato, e por motivos muito próximos ao do romance, é justificado como um efeito colateral, um meio para se atingir o objetivo pretendido. Assim, apesar do crime, o culpado fica sem castigo.

É o que explicita uma cena próxima do fim do filme, quando o protagonista se depara, de madrugada, com o fantasma de sua amante Nola e da vizinha idosa. Após o alerta de sua antiga amante de que ele havia deixado pistas e que seria preso, Chris responde que isso seria o mais "apropriado", pois indicaria um sinal de justiça, uma esperança, por menor que fosse, de que existe sentido na existência. Mas a justiça não vem e a tese de uma existência sem sentido prevalece. Ao ser questionado sobre a razão de ter matado a idosa, Chris diz que foi um efeito colateral e menciona Sófocles: "às vezes, o melhor é nem ter nascido" (PONTO, 2005).

Tal passagem se encontra em Édipo em Colono e vem expressa pelo coro:

Não ser nascido prevalece a todo argumento.

Mas, posto que se vem à luz, tornar célere para lá, de onde se veio, é o melhor a fazer (SÓFOCLES apud ZANIRATTO, 2003, p. 83, versos 1224-1227). 
Nietzsche recupera a ideia, mas a coloca na boca de Sileno, mestre de Dioniso, que teria respondido a Midas quando inquirido sobre o que era melhor para o homem:

Estirpe miserável e efêmera, filhos do acaso e do tormento! Por que me obrigas a dizer-te o que seria para ti mais salutar não ouvir? O melhor de tudo é para ti inteiramente inatingível: não ter nascido, não ser, nada ser. Depois disso, porém, o melhor para ti é logo morrer (NIETZSCHE, 1992, p. 36).

O tema também aparece no Eclesiastes (BÍBLIA, 1993, 4: 2-3): "Pelo que tenho por mais felizes os que já morreram, mais do que os que ainda vivem; porém mais que uns e outros tenho por feliz aquele que ainda não nasceu". Brás Cubas, nas Memórias póstumas, livro de cabeceira de Woody Allen, diz algo parecido: "Não tive filhos, não transmiti a nenhuma criatura o legado da nossa miséria" (ASSIS, 1990, p. 144), afirmação que, diga-se de passagem, exemplifica bem o imaginário trágico machadiano, que apresenta sempre o pior da existência sem nenhuma censura moral ou de outra ordem, afirmando-a por meio do humor que é característico de sua obra (ALMEIDA, 2015a). Podemos elencar ainda a máxima de Emil Cioran (2010), em Do inconveniente de ter nascido, segundo a qual ao nascer perdemos o mesmo que quando morremos, ou seja, tudo.

Independente do contexto, todos esses casos reafirmam a ausência de razão para existir, o que torna qualquer defesa racional da vida desnecessária e inútil. A ideia de que o pior da existência não é a morte, o assassinato ou qualquer outra maldade que possamos fazer, mas a própria existência - o fato de nascer para morrer - não deve ser confundida com uma visão pessimista. O que pode vir a ser pessimista é a possível reação, geralmente de desilusão, diante desse aspecto trágico da existência. São duas, em última análise, as reações possíveis: de um lado, afirmação incondicional da vida (filosofia trágica); de outro, a invenção de qualquer valor ou sentido abstrato pela negação do que se mostra desagradável.

É pela primeira via, da afirmação trágica, que se delineia o leitmotiv da fábula contada em Match point (2005): a vida é regida pelo acaso. Não há um 
sistema de mérito ou de justiça, apenas sorte - e seus "efeitos colaterais", como o azar da vizinha que nada tinha a ver com a história. Vale sublinhar que não está em jogo aqui a decisão do protagonista em cometer o duplo homicídio - que, de resto, poderia ter Ihe rendido uma vida inteira na prisão -, mas sim a questão mais ampla do acaso que culminou na ausência de punição. Nesse sentido, a argúcia de Woody Allen consiste em mostrar que o "engano" não ocorreu por parte de Chris cujo castigo não veio a acontecer, e sim por parte do espectador que, como o fantasma de Nola, talvez esperasse por um desfecho mais "adequado" à gravidade do delito.

Ora, essa adequação esperada requer um sentido implícito e mais precisamente determinados valores morais. Um dos aspectos da filosofia trágica, porém, consiste na inexistência de qualquer princípio externo ao real (como deus, justiça, verdade etc.) que possa ser invocado para compreender o real. Sob esse viés, os valores e significados que cotidianamente atribuímos aos fatos não os constituem e tampouco são inerentes ao mundo, pois são de ordem antropomórfica, ou seja, derivam do olhar humano sobre o mundo. Daí não se deduz, no entanto, que os significados e valores simplesmente não existem - o que seria tão absurdo quanto dizer que não há comunicação humana -, e sim que a existência do mundo e de todas as coisas não é diretamente afetada por nossos valores e significados.

Trata-se do contrário da noção de contingência ou consequência, que no âmbito moral indica o desencadeamento, a partir da ação humana, de certa recompensa ou castigo. Tal noção, como se sabe, foi amplamente explorada por Dostoiévski: a possibilidade de um crime sem castigo, sem remorsos e sem responsabilidade se resume à máxima niilista "sem Deus tudo é permitido". Ou ainda na problemática do indivíduo bondoso, puro e santo que numa sociedade corrompida aparece como vítima ingênua, socialmente inadequada: O idiota. Em ambos os casos, pressupõe-se que o valor ético depende das consequências de uma ação.

Recorremos, em contrapartida, ao argumento nietzschiano, em sua Genealogia da moral (NIETZSCHE, 1998, II, § 1), segundo o qual ao longo de quase toda a história humana teria vigorado a brutalidade da "moralidade dos 
costumes", ou seja, uma moral na qual o "bom" é o que é prescrito pelos costumes e tudo que é feito com base na imprevisibilidade da vontade individual é encarado como imoral. Tal moralidade tem como objetivo imediato, segundo Nietzsche, tornar o indivíduo previsível, uniforme.

Numa visada mais ampla, trata-se de dizer que, se valores não são fatos do mundo - pois não há como encontrar, factualmente, o bem/mal em si -, as consequências de uma ação não interferem na moralidade dos costumes. Tomemos, por exemplo, a ação da caridade, que costumeiramente é associada a valores como filantropia e altruísmo. Se nada garante quais serão as consequências dessa ação, então "o que mais vale é a intenção", ou seja, os valores atribuídos às ações dependem menos das consequências do que dos próprios valores previamente dados. Segue-se disso que, em suma, a moral estabelece o que pode e o que não pode ser aceito, evitado, desejado etc. A moral não se preocupa em diferenciar o que existe e o que não existe; em vez disso, ela opta deliberadamente por combater aspectos indesejáveis do que existe, mesmo que para isso precise inventar o que não existe.

A filosofia trágica opõe-se aos intentos de uma filosofia metafísica e moral, porque entende que a bondade e a maldade, a necessidade e a liberdade, o sentido e o sem sentido, as ideias e as ideologias não expressam qualquer aspecto do real; mais claramente, são estratégias para evitá-lo (OLIVA, 2001, p. 24). Nenhum valor, portanto, é capaz de determinar as consequências de uma ação, sobretudo no caso da ação geral de existir: tal como uma pedra atirada no ar, estamos submetidos a uma força que nos leva inevitavelmente a um mesmo fim. Esta força, por sua vez, não subsiste fora do mundo, mas coincide com ele, sendo nada mais que outro nome para o acaso da existência em sua absoluta indiferença para com a vida, a morte, os acontecimentos e os sentidos todos que atribuímos a eles.

A noção trágica de que a existência é indiferente aos valores que a ela atribuímos não implica, contudo, a defesa de uma não significação geral das coisas, isto é, a moral do niilismo. Pelo contrário, solicita o reconhecimento de que é tão somente na valoração - ou revaloração, em termos nietzschianos - que reside 
nossa "margem de manobra" em relação ao mundo: ou a aceitação plena de sua facticidade, ou a aceitação de certos fatos e não de outros. Em outras palavras, a escolha da aprovação ou reprovação é, em última instância, a única ação ética disponível ao indivíduo, já que em relação à existência como um todo nenhuma ação humana é capaz de alterar suas condições existenciais.

É nesses termos que Nietzsche pensava na noção de eterno retorno: uma disposição de desejar indistintamente todas as coisas, tanto as piores como as melhores. Sob esse prisma, bem e mal são indiferentes, pois aparecem sempre conjugados, interdependentes e ancorados a uma determinada moral, sem jamais constituírem um fato ou algo passível de fundamentação. Uma vez que o próprio existir é tão desnecessário quanto injustificável, o pensador trágico "não tem argumento algum para invocar em favor da existência, continua perfeitamente incapaz de dizer por que e em vista de que ele vive - e no entanto acha, doravante, a vida indiscutível e eternamente desejável" (ROSSET, 2000, p. 27).

Cumpre reiterarmos que nada aqui nos permite "justificar" moralmente um homicídio ou um adultério; não são as ações ou intenções que estão em jogo afinal, e sim a postura que assumimos em relação ao que acontece, ao que existe, ao que se vive. O pensamento trágico, portanto, nada tem a ver com uma conduta inconsequente (tudo vale porque nada vale), tampouco com uma passividade conformista (nada vale porque tudo vale). Quando vimos anteriormente que os valores são alheios à noção moral de consequência, não significa que não haja consequência alguma nas ações, mas apenas que uma coisa não determina a outra. Embora não haja, por exemplo, nenhuma garantia de recompensa a quem ajuda quem precisa, ou de castigo a quem deprecia o próximo, na ordem dos costumes os efeitos morais dessas atitudes já residem nelas mesmas: a recompensa da ajuda é a própria ação de ajudar, o castigo da depreciação é a própria ação de depreciar.

Valores inventados, enfim. Para o pensamento trágico, interessa mais a disposição do indivíduo em relação à existência como um todo. Assim, passando ao largo da esfera dos costumes, a questão ética na filosofia trágica é menos prescritiva do que descritiva: uma vez informados dos fatos do mundo (a morte 
é certa e não há nada que interfira no acaso da existência), podemos escolher acomodá-los aos nossos desejos ou, ao contrário, orientar nossos desejos conforme se mostram os fatos. Logo, recusa-se o que se mostra desagradável ou aprovase de forma incondicional a existência.

Claro que, em termos morais, nenhuma escolha é melhor que outra; se ambas conduzem a um mesmo fim, tanto faz o que se escolhe. Entretanto, no intervalo que dura uma existência individual, a negação seletiva de certos fatos em nome de qualquer natureza, ideal ou valor moral conduz inevitavelmente a um sofrimento que seria evitável. Afinal, se não há nada que possa nos assegurar que a vida seja regida por qualquer coisa além dela mesma, ela se impõe independentemente do modo como nos dispomos contra ou a favor de determinados fatos.

É nesse sentido que Woody Allen (apud LAX, 2008, p. 172) afirma que "a escolha está impregnada em nós. O sangue escolhe viver". Se nada do que fazemos, pensamos, acreditamos etc. pode interferir no que é, no acaso daquilo que nos é dado a viver, resta-nos o exercício constante de aprovação da vida sem outro fim senão a própria vontade de viver. Esse ponto nos conduz a retomar a poética narrativa de Match point (2005): trata-se de uma fábula que não contém uma proposta ética definida de antemão, mas que põe em evidência o acaso, a imprevisibilidade da vida e a ausência de sentido/valor inerentes.

Tal configuração poética logra em sintetizar a filosofia de Woody Allen conforme o próprio cineasta sentenciou (Ibid., p. 174). Ao mostrar que não há nenhum sentido a ser buscado no mundo, Allen não propõe que a existência seja vã e sem interesse ou que nos falte qualquer razão de viver. A questão é que nada falta à existência - ela é, ao contrário, demasiada, pois ela se basta, impondo a presença inelutável do acaso, que igualmente não repousa sobre fundamento algum. Dessa constatação deriva o principal elemento da filosofia de Woody Allen: a aprovação incondicional da existência, inclusive em seus aspectos mais dolorosos, desagradáveis e indigestos. Não porque haja algum tipo de prazer na dor, mas pela condição mesma de uma aprovação incondicional, que é, ao afirmar a vida, afirmá-la integralmente, com sua crueldade, efemeridade e finitude. 


\section{Considerações finais}

O objetivo a que nos propusemos neste artigo é, mais do que propor (mais) uma interpretação filosófica de Match point, demonstrar como tal película sintetiza o imaginário trágico de Woody Allen. Observamos que este não se dá somente pela constatação da "falta de sentido da vida e o horror da existência" (LAX, 2008, p. 402), mas principalmente pela aprovação incondicional dessa existência.

Assim como o cinema não se restringe a um enunciado moral, mas é capaz de tocar nos registros estético, filosófico, poético etc., algumas obras fílmicas possibilitam levantar interpretações não atreladas necessariamente ao discurso, implícito ou explícito, enunciado na tela. No caso de Woody Allen, encontramos sem dificuldade um horizonte trágico que convoca a escolha da aprovação. Não que ideias metafísicas ou moralistas sejam totalmente ausentes em suas obras, mas elas sempre se volatizam mediante o jogo das ocasiões e a revelação do acaso: esperanças que convivem com desilusões, crenças que se imbricam nas contradições humanas, mazelas que se imiscuem à alegria de viver. Sua motivação criativa, com efeito, parece consistir em fazer com que o trágico - que é sempre e por todos vivido - seja (re)visto, (re)apresentado e evidenciado, em vez de escondido, ignorado ou negado.

Em seus filmes, a representação de realidades desagradáveis jamais de realiza com pinceladas de indignação, revolta ou desaprovação, mas se figura com tintas carregadas de indiferença e, principalmente, humor - além do prazer inegável da criação cinematográfica, que se confunde com uma quase obsessão de produzir um filme por ano. A proliferação de discursos filosóficos, o gosto pela digressão existencial, o estilo dramático e irônico da narrativa são indícios de que, no cerne da obra de Woody Allen, subsiste uma tensão irresoluta entre o que há de pior da vida e o desejo de vivê-la, expressão de uma aprovação trágica. Afinal, "aos olhos da lógica do pior, a aprovação incondicional é com efeito, simultaneamente, a condição necessária das filosofias verdadeiramente trágicas e o signo que permite reconhecê-las imediatamente" (ROSSET, 1989, p. 51). 


\section{Referências}

A ROSA púrpura do Cairo. Direção: Woody Allen. Produção: Charles H. Joffe e Jack Rollins. Intérpretes: Mia Farrow; Jeff Daniels; Danny Aiello; Dianne Wiest e outros. Roteiro: Woody Allen. Los Angeles: Orion Pictures, 1985. (82 min.), son., color., $35 \mathrm{~mm}$.

ALMEIDA, R. Meia-noite em Paris. In: ALMEIDA, R.; FERREIRA-SANTOS, M. Cinema e contemporaneidade. São Paulo: Képos, 2012. p. 39-52.

. O imaginário trágico de Machado de Assis: elementos para uma pedagogia da escolha. São Paulo: Képos, 2015a.

. O mundo, os homens e suas obras: filosofia trágica e pedagogia da escolha. Tese (Livre Docência em Cultura e Educação) - Faculdade de Educação, Universidade de São Paulo, São Paulo: FEUSP, 2015b.

Cinema e educação: fundamentos e perspectivas. Educação em Revista, Belo Horizonte, n. 33, p. 1-28, 2017.

ASSIS, M. Memórias póstumas de Brás Cubas. São Paulo: Ática, 1990.

BECCARI, M. Articulações simbólicas: uma nova filosofia do design. Teresópolis: $2 A B, 2016$.

BÍBLIA. A. T. Eclesiastes 4: 2-3. Trad. João Ferreira de Almeida revista e atualizada. 1993. Disponível em: <https://goo.gl/cpporm>. Acesso em: 11 out. 2017.

CIORAN, E. M. Do inconveniente de ter nascido. Lisboa: Letra Livre, 2010. 
CRIMES e pecados. Direção: Woody Allen. Produção: Charles H. Joffe e Jack Rollins. Intérpretes: Martin Landau; Woody Allen; Bill Bernstein e outros. Roteiro: Woody Allen. Los Angeles: Jack Rollins \& Charles H. Joffe Productions, 1989. (104 min.), son., color., $35 \mathrm{~mm}$.

DELEUZE, G. Cinema: imagem-movimento. São Paulo: Brasiliense, 1985.

LAX, E. Conversas com Woody Allen. São Paulo: Cosac Naify, 2008.

MAGIA ao luar. Direção: Woody Allen. Produção: Ronald L. Chez. Intérpretes: Colin Firth; Emma Stone; Marcia Gay Harden e outros. Roteiro: Woody Allen. Londres: Dippermouth Productions, 2014. (97 min.), son., color., $35 \mathrm{~mm}$.

MEIA-NOITE em Paris. Direção: Woody Allen. Produção: Javier Méndez. Intérpretes: Owen Wilson; Rachel McAdams; Kathy Bates e outros. Roteiro: Woody Allen. Barcelona: Mediapro; Versátil Cinema; Gravier Productions; Pontchartrain Productions; TV3, 2011. (94 min.), son., color., $35 \mathrm{~mm}$.

MERLEAU-PONTY, M. O cinema e a nova psicologia. In: XAVIER, I. (Org.). A experiência do cinema. Rio de Janeiro: Graal, 1983. p. 101-117.

NIETZSCHE, F. O nascimento da tragédia ou helenismo e pessimismo. Tradução J. Guinsburg. São Paulo: Companhia das Letras, 1992.

. Ecce homo: como alguém se torna o que é. Tradução Paulo César de Souza. São Paulo: Companhia das Letras, 1995.

Genealogia da moral: uma polêmica. Tradução Paulo César de Souza. São Paulo: Companhia das Letras, 1998. 
OLIVA, R. H. El saber trágico: de Nietzsche a Rosset. Madrid: Laberinto, 2001.

PONTO final: Match point. Direção: Woody Allen. Produção: Stephen Tenenbaum. Intérpretes: Scarlett Johansson; Jonathan Rhys Meyers; Emily Mortimer e outros. Roteiro: Woody Allen. Londres: BBC Films; Thema Production; Jada Productions; Kudu Films, 2005. (124 min.), son., color., 35 mm.

REIA-BAPTISTA, V. Estudos fílmicos: o estado da Arte (e da Ciência). In: SOPCOM, 4., 2005, Faro. Livro de Actas. Faro: Universidade do Algarve, jun. 2005. p. 10291033. Disponível em: <https://goo.gl/h6HeLY>. Acesso em: 10 maio 2017.

RICOEUR, P. Hermenêutica e ideologias. Petrópolis: Vozes, 2008.

ROSSET, C. A lógica do pior: elementos para uma filosofia trágica. Tradução Fernando J. F. Ribeiro e Ivana Bentes. Rio de Janeiro: Espaço e Tempo, 1989.

Alegria: a força maior. Tradução Eloisa Araújo Ribeiro. Rio de Janeiro: Relume-Dumará, 2000. (Coleção Conexões).

SCHEMBRI, J. Words from Woody. The Age, mar. 2006. Disponível em: <https://goo.gl/Evsoe5>. Acesso em: 10 maio 2017.

STEINER, G. Depois de Babel: questões de linguagem e tradução. Curitiba: Editora da UFPR, 2005.

ZANIRATTO, C. P. Tradução, comentário e notas de Édipo em Colono de Sófocles. 2003. Dissertação (Mestrado em Linguística) - Instituto de Estudos da Linguagem, Unicamp, Campinas, 2003. 